\title{
is Research Square \\ Use of Intranasal Analgesia in Military Setting: a French Cross Sectional Survey
}

\section{Romain MONTAGNON ( $\nabla$ r.montagnon@yahoo.fr)}

HIA Sainte Anne https://orcid.org/0000-0002-1274-677X

\section{Pierre-Julien CUNGI}

HIA Sainte Anne

\section{Gabriel MORAND}

French Military Health Service

\section{Jérôme DESMOTTES}

HIA Sainte Anne

\section{Pierre PASQUIER}

HIA Percy: Hopital d'Instruction des Armees Percy

\section{Stéphane TRAVERS}

French Military Health Service

\section{Luc AIGLE}

French Military Health Service

Christophe DUBECQ

French Military Health Service

\section{Research}

Keywords: Intranasal route, disaster medicine, emergency medicine, pre-hospital care, military medicine, analgesia

Posted Date: February 3rd, 2021

DOI: https://doi.org/10.21203/rs.3.rs-184043/v1

License: @ (i) This work is licensed under a Creative Commons Attribution 4.0 International License.

Read Full License 


\section{Abstract}

\section{Background}

For military physicians, practice in tactical and austere environments, particularly during deployments, requires optimized pain management. Several recent studies have shown a definite interest in the intranasal (IN) route for analgesia. Few published series show efficacy and variable times of action depending on the drug used (ketamine, sufentanil and fentanyl), with exceptional side effects. The aim of this study is to evaluate the medical practice of the French Military Health Service (FMHS) physicians.

\section{Methods}

We carried out a declarative and multicentric survey from January 15, 2020, to April 14, 2020. The surveyed population was the physicians of the FMHS, 727 working in medical units and 55 in emergency departments (EDs) in France and overseas.

\section{Results}

In all, 259 responses were collected, giving a $33 \%$ return rate; $77.6 \%$ of physicians reported being familiar with the IN route for analgesia. However, only $18.4 \%$ had already used it. Physicians trained in emergency medicine and assigned to highly operational units were more familiar with this route and used it more frequently. The most common drug used was ketamine (51\%). Finally, $90 \%$ of respondents expressed an interest in training and use of intranasal analgesia.

\section{Conclusions}

If a majority of physicians from the FMHS are familiar with IN analgesia, only few use it in practice. Therefore, specific training is suitable to improve this knowledge and homogenize guidelines. Having been the subject of numerous studies in progress in civilian and military medicine, the IN route seems to be a promising solution for remote and austere environments.

\section{Background}

Pain treatment is a major factor in the overall management of patient care. Yet, almost half of general practitioners (GPs) feel that they have received insufficient training in this domain (1-2). In military setting, optimum management of analgesia is a key point of combat casualty care (3-4). A lack of effective analgesia could be correlated with increased morbidity and mortality in combat setting (5). In modern conflicts, as the Barkhane Operation in the Sahel-Saharan Strip, the distances (up to $1100 \mathrm{~km}$ ) can be very long and the evacuation to a field hospital can take many hours (6-7). In these situations, the appropriate treatment for prehospital analgesia is sometimes limited, or delayed, because of the lack of intravenous (IV) access. To cope with such problems, the intranasal (IN) route appears as a useful one for pain control, being both rapid and non-invasive (8). Although this has long been a recognized technique, it has not been extensively employed. 
The nasal mucosa is highly vascular, with numerous capillaries, providing an exchange surface estimated to be $120-150 \mathrm{~cm}^{2}$ (9). However, certain factors, such as a severely deviated nasal septum, some vasoconstrictors, or intranasal hemorrhage, could reduce absorption across the mucous membrane. The IN route is also contraindicated in cases of facial trauma (risk of osteo-meningeal breach) (10). When the IN route is used, it is important to deliver high-quality pulverization with good diffusion over the entire nasal mucosa. A posterior spurt with droplets that are too big or a large overall volume both need to be avoided. The optimal droplet size seems to be below 300 microns. In addition, the mucous membrane reaches a saturation point with an administered volume of about $0.5 \mathrm{ml}$ per nostril. A specific nasal spray is already available (Mucosal Atomization Device ${ }^{\circledR}$, MAD Nasal ${ }^{\mathrm{TM}}$, Teleflex., Morrisville, NC, USA). Adapted for use with a syringe, this device provides a fine mist of particles, 30-100 microns in size, and a better bioavailability of the medication (11). The efficacy and speed of the drug activity delivered by the IN route depends on absorption across the nasal mucosa. This is determined by three factors: the size of the droplets (dependent on the device used), the $\mathrm{pH}$, and the liposoluble nature of the molecules administered.

Three substances are of value for intranasal analgesia: ketamine (40\%), sufentanil (78\%) and fentanyl (90\%) (12). Used at low doses, ketamine has a powerful analgesic effect (13). At doses of 0.5-0.75 $\mathrm{mg} / \mathrm{kg}$, IN ketamine is considered as a rapid and effective drug for acute pain control (14-15). With this form of administration, ketamine is detectable in the blood after 2 minutes. A maximum concentration is reached after 30 minutes, and it is estimated to be effective for 3 hours. The average bioavailability of ketamine delivered via the IN route is $40 \%$, within a range of $33-71 \%(16-18)$. The PAIN-K study, randomized controlled trials using a double-blind vs. placebo protocol, demonstrated the efficacy of IN ketamine, at a dose of $0.75 \mathrm{mg} / \mathrm{kg}$, for acute pain control (Numeric Rating Scale [NRS] $\geq 5$ ), without any significant adverse effects (19). Sufentanil is a well-known substance used in IN analgesia (20). Several randomized studies have compared IN sufentanil with intravenous (IV) morphine for acute pain control in emergency departments. At doses of $0.7 \mu \mathrm{g} / \mathrm{kg}(21)$ or $0.4 \mu \mathrm{g} / \mathrm{kg}$ (22), IN sufentanil provides rapid, reliable and effective pain control, comparable with that of IV morphine. IN sufentanil titration is possible with an initial bolus dose of $0.3 \mu \mathrm{g} / \mathrm{kg}$, then $0.15 \mu \mathrm{g} / \mathrm{kg}$ at 10 minutes and again at 20 minutes (if the NRS $\triangle 3$ ) (23). The majority of studies on the use of IN fentanyl have involved pediatric patients (24-25). In the case of a child suffering severe pain, a $1.5 \mu \mathrm{g} / \mathrm{kg}$ dose of IN fentanyl is a safe and effective alternative to oral or parenteral administration of opioids (26).

There is still a paucity of information in the literature on the IN route of analgesia, and randomized double-blind trials are scarce. The small number of publications indicates the value of this technique, variable durations and levels of efficacy depending on the drug used, and only a few minor adverse effects. To our knowledge, no study has, as yet, assessed the use of IN analgesia in a military context (16).

The objective of this study is to evaluate the medical practice of the French Military Health Service (FMHS) physicians regarding the current understanding and use of IN analgesia. 


\section{Methods}

\section{Study population}

We carried out an anonymous, multicenter and declared study from January 15, 2020, to April 14, 2020. The study group comprised all the GPs and emergency medicine physicians of the FMHS -727 doctors practicing in France and overseas together with 55 doctors in the emergency departments (EDs) of the eight military training hospitals (MTHs) (Clamart, Saint- Mandé, Toulon, Marseille, Lyon, Metz, Bordeaux and Brest). Physicians without a specialized qualification in general medicine were excluded.

\section{Data collection}

A 16 questions - survey was sent out by the Administration services of Military Medicine (Direction de la médecine des forces), via the "Intradef" network, to French military physicians in different medical centers. For the doctors working in the EDs, the researchers contacted the Head of ED in each hospital. The questionnaire was prepared on the "JotForm" site (www.jotform.com), and it was first sent out on January 15, 2020, followed by three reminders by email on February 5, March 5 and April 5, 2020.The physicians involved were offered different ways of returning the completed questionnaires: either access using an Internet link, a "QR code," or the possibility of downloading the questionnaire from the email, as a Word document or PDF, and then sending it back to the researchers by email.

The survey was divided into four parts: biographical details, assessment of related knowledge, the use of IN analgesia, and the relative value of this technique in practice. In addition, for those physicians familiar with the IN technique, five additional multi-choice questions were added. The latter concerned the rapidity of pain control by the IN route, familiarity with the nasal MAD device, and the bioavailability of the different substances delivered via the IN route (ketamine, sufentanil and fentanyl). A mark out of 5 was attributed each time, according to the answers given (Annex $A$ ).

The computerized data collected was then transcribed into a table, using an Excel program (version 10, Redmond, WA).

\section{Statistical analysis}

The quantitative variables are shown as average values, with standard deviation and range $(x,+/-$ standard deviation, min-max). The quantitative data from the different groups were compared using Student's T-test or the Mann-Whitney U test, provided that the necessary parameters were met.

The qualitative variables are shown as percentages. They were compared using the Chi-squared test or the Fisher's exact test if the theoretical numbers were insufficient. Where several tests were carried out, the " $p$ " value was adjusted using the Bonferroni correction. If, from the numbers collected, it was possible to perform a multivariable data analysis, a stepwise logistic regression was applied using the likelihood ratio test. Subsequently, the goodness-of-fit of our logistic regression model was verified with the Hosmer- 
Lemeshow test. All statistical tests were performed using IBM SPPS 25.00 software (IBM Corp. IBM SPSS Statistics for Windows, Version 25.0. Armonk, NY).

\section{Results}

\section{Description of the sample population}

Two hundred and fifty-nine responses were collected during the study period, giving a 33\% return rate. Only one questionnaire was rejected, because it had been completed by an anesthetist. The final sample comprised 118 women and 141 men, and the average age was 36.2 years: 35 years $(+/-6,27-57)$ for the women and 37 years $(+/-7,27-61)$ for the men.

The majority $(65.6 \%)$ of respondents had been practicing medicine for $<10$ years, and $68.6 \%$ of the sample group had followed specialized training courses in emergency medicine. In all, $58.3 \%$ of these physicians were on-call in emergency services (EDs or pre-hospital care). Physicians working for the Army accounted for $41.3 \%$ of the responses, with 107 completed questionnaires, followed by the Air Force with 33 questionnaires completed (Table 1). Within the FMHS, 305 of the physicians interviewed were working for the Army and we had a 35\% response rate; 80 physicians were working for the Air Force and the response rate was $41.2 \%$; and, finally, 98 were working for the Navy and we had a response rate of $19.4 \%$. Hence, our sample group is not significantly different from the study population $(p=0.085)$. 
Table 1

Population

$\mathbf{n}$

Years of practice

$<5$ years

5 to 10 years

10 to 15 years

$>15$ years

Additional training in emergency medicine

DESCMU*

CAMU**

No additional training

On-call for emergency department (ED) or pre-hospital (PH) on call

ED

$\mathrm{PH}$

$\mathrm{ED}$ and $\mathrm{PH}$

No

\section{If yes, how often?}

1 to 2 times per month

3 to 5 times per month

$>5$ times per month
87

83

47

42

24

138

97

70

20

61

108

68

59

24

9.3

53.3

37.5

18.1

16.2

33.6

32

97

27

7.7

23.6

41.7
45

39.1

15.9

\section{Deployed abroad for operations ( $>2$ months)}

0 to 2 times

2 to 6 times

6 to 8 times

8 to 10 times

$>10$ times
114

110

19

7

9

\section{Unit}

Army 


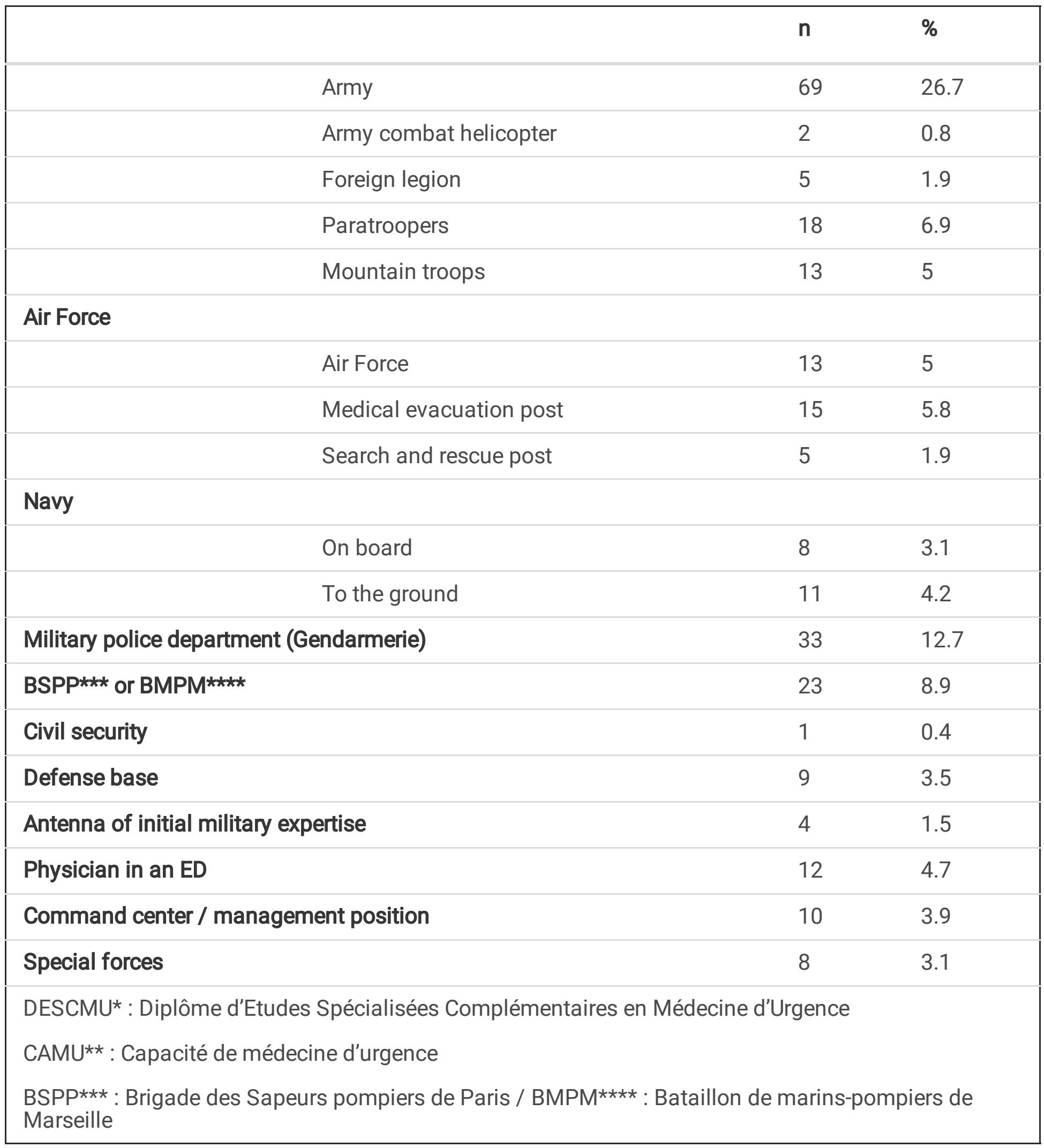

\section{Knowledge of the IN route for analgesia}

Within the sample group, 201 physicians (77.6\%) stated that they were familiar with the IN route of analgesia when treating a traumatized patient. Their knowledge of this technique was mainly derived 
from reading scientific articles, either civilian (28.9\%) or military (18.3\%). Alternatively, a conference lecture $(19.7 \%)$ or discussions with colleagues $(16.8 \%)$ were also sources of information. Consequently, these 201 physicians answered the five relevant questions. We noted $45.3 \%$ correct replies for the time taken for the IN route to be effective (1 to 15 minutes), but only $28.7 \%$ were aware of the nasal MAD device. The majority of the group (67.2\%) knew the bioavailability of sufentanil when administered by the IN route (75-100\%), but the percentage of correct responses was lower regarding the bioavailability of the other substances: $15.4 \%$ for ketamine and $14.9 \%$ for fentanyl. Only 33 of the physicians $(16.5 \%)$ had a final mark $\geq 3$ out of 5 . Knowledge of IN analgesia is greater in the more recently qualified doctors who have been practicing for $<5$ years $(p<0.018)$ or who have followed supplementary training in emergency medicine $(p<0.001)$ or those who have been on-call in hospitals and in pre-hospital care $(p<0.001)$. However, the number of on-call duties did not seem to affect the extent of this knowledge as much as the number of deployments carried out $(p<0.01)$. Finally, those physicians who are assigned to highly operational units or units working in austere environments are more familiar with the IN route of analgesia $(p<0.01)($ Table 2$)$. The multivariable analysis that we performed supports these results (Fig. 1). 
Table 2

Knowledge about intranasal route

\begin{tabular}{|c|c|c|c|c|c|}
\hline & No $(n)$ & Yes (n) & $\%$ & Total & $\mathbf{p}$ \\
\hline \multicolumn{6}{|l|}{ Years of practice } \\
\hline$<5$ years & 12 & 75 & 86.2 & 87 & \multirow[t]{2}{*}{0.0184} \\
\hline$>5$ years & 46 & 126 & 73.3 & 172 & \\
\hline $5-10$ years & 20 & 63 & & 83 & \\
\hline $10-15$ years & 17 & 30 & & 47 & \\
\hline$>15$ years & 9 & 33 & & 42 & \\
\hline \multicolumn{6}{|l|}{ Additional training in emergency medicine (EM) } \\
\hline No additional training in EM & 38 & 59 & 60.8 & 97 & \multirow[t]{2}{*}{$<0.001$} \\
\hline Additional training in EM & 20 & 142 & 87.7 & 162 & \\
\hline DESCMU* & 2 & 22 & & 24 & \\
\hline CAMU** & 18 & 120 & & 138 & \\
\hline \multicolumn{6}{|c|}{ On call for emergency department (ED) or pre-hospital (PH) on call } \\
\hline No & 40 & 68 & 63 & 108 & \multirow[t]{2}{*}{$<0.001$} \\
\hline \multirow[t]{4}{*}{ Yes } & 18 & 133 & 88.1 & 151 & \\
\hline & 13 & 57 & & 70 & \\
\hline & 0 & 20 & & 20 & \\
\hline & 5 & 56 & & 61 & \\
\hline \multicolumn{6}{|l|}{ If so, how often? } \\
\hline 0 to 2 times per month & 10 & 58 & & 68 & \multirow[t]{3}{*}{ NS } \\
\hline 3 to 5 times per month & 7 & 52 & & 59 & \\
\hline$>5$ times per month & 1 & 23 & & 24 & \\
\hline \multicolumn{6}{|c|}{ Number of deployments/missions abroad ( $>2$ months) } \\
\hline$<6$ times & 56 & 168 & 75 & 224 & \multirow[t]{2}{*}{$<0.01$} \\
\hline$>6$ times & 2 & 33 & 94.3 & 35 & \\
\hline \multicolumn{6}{|l|}{ Unit } \\
\hline "Special environment units"** & 6 & 87 & 93.5 & 93 & $<0.001$ \\
\hline
\end{tabular}




\begin{tabular}{|c|c|c|c|c|c|}
\hline & No (n) & Yes (n) & $\%$ & Total & $p$ \\
\hline Other units & 52 & 114 & 68.7 & 166 & \\
\hline \multicolumn{6}{|c|}{ 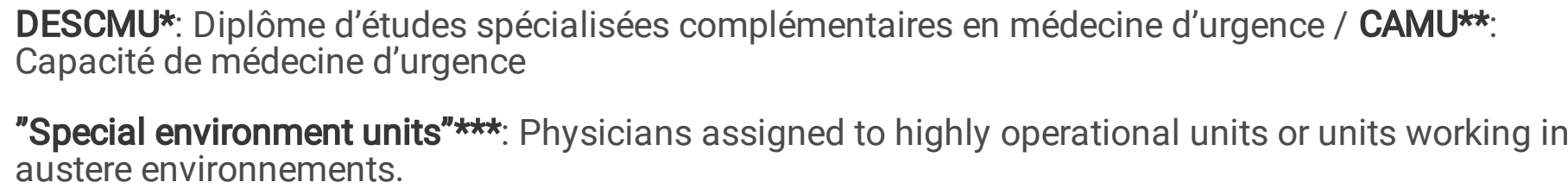 } \\
\hline
\end{tabular}

\section{Use of the IN route}

A total of 47 physicians (18.4\%) from the sample population stated that they had already used IN analgesia when treating a trauma patient, mainly in France (71.3\%) in pre-hospital setting (52.4\%). Deployments represent quite an area of significant usage too (28.6\%). The drug used in $51 \%$ of cases was ketamine, either (in 34\% of usages) administered alone or (in 17\% of usages) administered with midazolam. The second most frequently prescribed drug was sufentanil (19\%). In the sample, fentanyl was seldom used (4\%). Some physicians have already used ketamine and sufentanil (11\%), ketamine/midazolam or sufentanil alone (6\%). Furthermore, some physicians have used midazolam alone (9\%) (Fig. 2). In the majority of cases, no side effects were observed with ketamine $(64.5 \%)$ or with the opioids (82\%). However, psychodysleptic side effects have been reported by $29 \%$ of physicians when administering ketamine by the IN route. Slightly more than half of doctors $(52.3 \%)$ have stated that additional pain control was necessary after using the IN route. In this case, the analgesic was delivered intravenously by $91.3 \%$ of the respondents.

In summary, IN analgesia is more prevalent if the doctor has followed supplementary specialized training in emergency medicine $(p<0.001)$, has been on-call in a hospital or a pre-hospital context $(p<0.001)$, or if he/she has been part of a highly operational unit or units working in austere environments $(p<0.01)$ (Table 3). 
Table 3

Use of intranasal route for analgesia

\begin{tabular}{|c|c|c|c|c|c|}
\hline & No (n) & Yes (n) & $\%$ & Total & $\mathbf{p}$ \\
\hline \multicolumn{6}{|l|}{ Years of practice } \\
\hline$<5$ years & 73 & 13 & & 86 & \multirow[t]{4}{*}{ NS } \\
\hline $5-10$ years & 66 & 17 & & 83 & \\
\hline $10-15$ years & 40 & 6 & & 46 & \\
\hline$>15$ years & 30 & 11 & & 41 & \\
\hline \multicolumn{6}{|c|}{ Additional training in emergency medicine (EM) } \\
\hline No additional training in EM & 89 & 8 & 8.2 & 97 & \multirow[t]{2}{*}{$<0.001$} \\
\hline Additional training in EM & 120 & 39 & 24.5 & 159 & \\
\hline DESCMU* & 15 & 8 & & 23 & \\
\hline CAMU** & 105 & 31 & & 136 & \\
\hline \multicolumn{6}{|c|}{ On call for emergency department (ED) or pre-hospital $(\mathrm{PH})$ on call } \\
\hline No & 95 & 12 & 11.2 & 107 & \multirow[t]{2}{*}{0.0139} \\
\hline Yes & 114 & 35 & 23.5 & 149 & \\
\hline ED & 60 & 10 & & 70 & \\
\hline $\mathrm{PH}$ & 14 & 6 & & 20 & \\
\hline $\mathrm{ED}$ and $\mathrm{PH}$ & 40 & 19 & & 59 & \\
\hline \multicolumn{6}{|l|}{ If so, how often? } \\
\hline 0 to 2 times per month & 59 & 8 & & 67 & \multirow[t]{3}{*}{ NS } \\
\hline 3 to 5 times per month & 40 & 18 & & 58 & \\
\hline$>5$ times per month & 15 & 9 & & 24 & \\
\hline \multicolumn{6}{|c|}{ Number of deployments/missions abroad ( $>2$ months) } \\
\hline$<6$ times & 185 & 37 & 16.7 & 222 & \multirow[t]{2}{*}{0.094} \\
\hline$>6$ times & 24 & 10 & 29.4 & 34 & \\
\hline \multicolumn{6}{|l|}{ Unit } \\
\hline 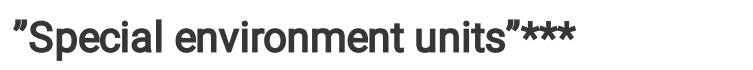 & 66 & 26 & 28.3 & 92 & \multirow[t]{2}{*}{0.0038} \\
\hline Other units & 143 & 21 & 12.8 & 164 & \\
\hline
\end{tabular}




\section{No $(n) \quad$ Yes $(n) \quad \% \quad$ Total $\quad p$}

DESCMU*: Diplôme d'études spécialisées complémentaires en médecine d'urgence / CAMU**: Capacité de médecine d'urgence

"Special environment units"***: Physicians assigned to highly operational units or units working in austere environnements.

\section{Importance of the IN route}

A total of 234 doctors declared an interest in following a training course on IN analgesia. For the majority of them, they would use the IN route for analgesia in France and during deployments (84.1\%). Only 94 physicians (10.3\%) stated that they would use the IN route in a medical center in France. In the sample group, $49.8 \%$ of the physicians considered that the level of competence required for employing the IN route is that of a nurse. Another 70 physicians $(27 \%)$ considered medical training at the level of a combat medic was sufficient and $7.3 \%$ considered that this technique should only be used by qualified doctors.

\section{Discussion}

The aim of this study was to assess the level of knowledge of IN analgesia among FMHS physicians. The majority $(77.6 \%)$ of physicians in the sample group stated that they were well acquainted with the technique of IN analgesia. However, only four physicians scored a maximum mark of five out of five on the multi-choice questions; $90.7 \%$ of the respondents declared an interest in following a specific training course on IN pain control. Although the FMHS doctors know about this technique, some supplementary training is necessary, together with the establishment of standardized protocols.

Civilian (28.9\%) and military (18.3\%) scientific articles or discussions between peers $(16.8 \%)$ are the main sources of information for this method of analgesia. Only a small percentage (3.7\%) know the IN route thanks to a training course, given at the Ecole du Val-de-Grâce (the French military medical academy), during a dedicated module on tactical management of combat casualties (27).

In all,62.5\% of the sample group had a qualification in emergency medicine. Such training in emergency medicine is fundamental for a military GP as it gives the physician an indispensable level of autonomy in deployments in austere setting. For example, during French military operations in the Sahel (an area 10 times as wide as France), the evacuation time between the combat zone and the nearest field hospital can reach 6 to 12 hours (6-7). The frontline GPs and emergency medicine physicians, assisted by the nurses and combat medics, need to take complete charge of patients in very rudimentary conditions. The practice of emergency medicine is an important factor in the degree of knowledge concerning IN analgesia. Qualified personnel who regularly work in emergency medicine use this technique more than others. 
Our study highlights the need for an initial training course, which could be provided by the Ecole du Valde-Grâce (the French military medical academy), either at the end of the internship period, as a supplementary module, or prior to departure on deployment, as part of the tactical management of combat casualties. The results also underline the need for continuous professional development, both theoretical and practical, as regards IN analgesia. The FMHS physicians provide the medical support of military units during various missions involving very different field conditions. This governs the degree of engagement of these physicians in the medical outposts. The sea, mountains, and airborne or special operations are particularly austere environments, exacting and isolating for the soldiers but equally so for the physicians supporting them. From the respondents, the researchers have arbitrarily taken a sample of physicians who are assigned to highly operational units (Special Forces/GIGN [National Gendarmerie Intervention Group], paratroopers, medical evacuation [MEDEVAC] and search and rescue [SAR]) and naval embarkation units) or who are deployed in specific situations (mountain troops, Civil Security, BSPP (Paris Fire Brigade) and BMPM (Marseille Naval Fire Battalion)). The physicians assigned to these units have more knowledge of, and are more likely to use, IN analgesia.

Only a small proportion of the doctors questioned had already used the IN route for pain control and then mainly in pre-hospital medical care and in France. The most frequently used drug is ketamine, alone or in association with midazolam. Ketamine is a substance that is well-known to military physicians, because it is reliable and efficacious in controlling acute pain on the battlefield (28). Ketamine has the effect of stimulating the cardiovascular system (central sympathomimetic action) while having little effect on ventilation (28). In association with midazolam, the psychodysleptic side effects seen with IN ketamine are reduced. However, to our knowledge, no study has yet proven that joint administration of ketamine and midazolam diminishes this side effect. Four of the doctors used midazolam on its own but given that this drug has hypnotic properties it would seem to be more appropriate for sedation (of psychotic patients for instance) rather than pain control.

Despite the more numerous studies on the use of opioids (sufentanil and fentanyl) in IN analgesia, particularly in a pre-hospital context, both drugs are less frequently used by military doctors ( $23 \%$ of use). These substances are more lipophilic than ketamine and, consequently, the molecules are absorbed better by the nasal mucosa. However, because of their hypotensive properties and certain adverse effects, notably reducing respiration, they merit caution as regards their use for a combat casualty with hemorrhagic shock. On the other hand, an advantage of this class of therapeutics is the possibility of reversing any major adverse effects by the administration of an antidote (naloxone), initially using the same delivery route. The IN administration of this drug is available to non-medical professionals (police, paramedics etc.) in the USA for treating victims of an opioid overdose (29).

In our sample group, the physicians showed a preference, on national territory at least, for using ketamine. In familiarizing themselves with this drug, they will be capable of using it for a combat casualty in a critical state during deployments. 
Several procedures are currently being introduced to extend the use of IN analgesia into combat zones. Those military doctors whose role is supporting the National Gendarmerie Intervention Group (GIGN) have put in place a protocol for administering sufentanil and ketamine via the IN route (30). At the moment, the MAD device is only available on demand in exceptional cases during deployments, but it should be available for routine ordering from 2021 onwards.

Finally, a ketamine pulverization device for IN analgesia is being developed currently by the FMHS Central Pharmacy and this could soon be made available as a means of auto-administration for all servicemen and women. The idea is to include this device in the personal kit of each soldier, actually this kit is composed of a morphine syrette (a $10 \mathrm{mg}$ subcutaneous dose) for analgesia (31). It would be interesting to carry out a new study in a few year to assess the impact of introducing both these standardized guidelines and the new injection device on the level of knowledge and application of this method of analgesia.

\section{Limitations}

Despite the three reminders made to increase the response rate, the low response rate of $33 \%$ could be explained by a significant number of military physicians on deployment over our study period. During deployment in overseas military operations, it is more complicated to have access to one's mailbox. Moreover, some physicians may not have been interested in this survey about the IN route and therefore did not respond. Because of this selection bias, it is possible that physicians interested in this technique are over-represented in this study.

\section{Conclusions}

In this study, a majority (78\%) of physicians from the FMHS reported being familiar with IN analgesia, but only a few $(18 \%)$ declared using it in practice. Knowledge and use of the IN technique varied according to the dedicated training courses followed previously, whether the physician has been on-call in the hospital or pre-hospital emergency services, and the type of military unit supported. Therefore, specific training should be considered to promote the use of IN analgesia and harmonize practices. Specific studies, both civilian and military, are still needed to further promote the use of the intranasal route for optimized pain management in remote and austere environments.

\section{List Of Abbreviations}

- IN: intranasal

- FMHS: French Military Health Service

- EDs: Emergency Departments

- GPs: General Practitioners

- IV: intravenous 
- NRS: Numeric Rating Scale

- MTHs: Military Training Hospitals

- MAD Device: Mucosal Atomization Device ${ }^{\circledR}$, MAD Nasal ${ }^{T M}$, Teleflex., Morrisville, NC, USA.

- GIGN: Groupe d'Intervention de la Gendarmerie Nationale: National Gendarmerie Intervention Group

- MEDEVAC: medical evacuation

- SAR: Search and Rescue

- BSPP: Brigade de Sapeurs-Pompiers de Paris: Paris Fire Brigade

- BMPM: Bataillon de Marins-Pompiers de Marseille: Marseille Naval Fire Battalion

\section{Declarations}

\section{Ethics approval and consent to participate:}

The necessary scientific and ethical approval was obtained from the Head of Training, of Research and of Innovation in the FMHS in December 2019 (Project validation no. 2019PHJ20).

\section{Consent for publication:}

Not applicable.

\section{Availability of data and materials:}

The datasets used and/or analysed during the current study are available from the corresponding author on reasonable request.

\section{Competing interests:}

The authors declare that they have no competing interests.

\section{Funding:}

Not applicable.

\section{Authors' contributions:}

Study concept and design (MR, CPJ, MG, DJ, PP, TS, AL, DC); acquisition of data (MR, DC); analysis of data (MR, CPJ, DC); drafting of manuscript (MR, CPJ, MG, DJ, DC); revision of manuscript (DC, PP, TS, $A L$ ); All authors read and approved the final manuscript.

\section{Acknowledgements:}

The authors thank both the researchers and the responders of the survey. The authors pay also a great tribute to the service members of the French Military Medical Service who are deployed in overseas 
military operations.

\section{References}

1. Tajfel P, Gerche S, Huas D. La Douleur en Médecine Générale. Doul et Analg 2002;15:71-79.

2. Huas $D$, Tajfel $P$, Gerche $S$. Prévalence et Prise en Charge de la Douleur en Médecine Générale. Rev Prat 2000;14:1837-1841.

3. Butler FK, Kotwal RS, Buckenmaier CC 3rd, et al. A Triple-Option Analgesia Plan for Tactical Combat Casualty Care: TCCC Guidelines Change 13-04. J Spec Oper Med 2014;14:13-25.

4. Benov A, Salas MM, Nakar $\mathrm{H}$, et al. Battlefield pain management: A view of 17 years in Israel Defense Forces. J Trauma Acute Care Surg 2017;83:150-155.

5. Buckenmaier CC 3rd, Rupprecht C, McKnight G, et al. Pain Following Battlefield Injury and Evacuation: A Survey of 110 Casualties from the Wars in Iraq and Afghanistan. Pain Med 2009;10:1487-1496.

6. Travers S, Carfantan C, Luft A, et al. Five years of prolonged field care: prehospital challenges during recent French military operations. Transfusion 2019;59:1459-1466.

7. Vitalis V, Carfantan C, Montcriol A, et al. Early transfusion on battlefield before admission to role 2: A preliminary observational study during "Barkhane" operation in Sahel. Injury 2018; 49:903-910.

8. Grassin-Delyle S, Buenestado A, Naline E, et al. Intranasal Drug Delivery: An Efficient and NonInvasive Route for Systemic Administration: Focus on Opioids. Pharmacol Ther 2012;134:366-379.

9. Jacques J.-M. Utilisation de la Voie Intranasale en Médecine D'Urgence. Louvain Med 2016;135:223230.

10. Dale O. Intranasal Administration of Opioids/Fentanyl Physiological and Pharmacological Aspects. Eur J Pain Suppl 2010;4:187-190.

11. Fantacci C, Fabrizio GC, Ferrara P, et al. Intranasal Drug Administration for Procedural Sedation in Children Admitted to Pediatric Emergency Room. Eur Rev Med Pharmacol Sci 2018;22:217-222.

12. Lemoel F. Gestion de la Douleur Traumatique en Urgence Par Voie Intra Nasale. Proceedings of the COPACAMU; 2016 Mars 17-18; Marseille, France.

13. Orser BA, Pennefather PS, MacDonald JF. Multiple Mechanisms of Ketamine Blockade of N-MethylD-Aspartate Receptors. Anesthesiology 1997;86:903-917.

14. Carr D, Goudas L, Denman W, et al. Safety and Efficacy of Intranasal Ketamine for the Treatment of Breakthrough Pain in Patients with Chronic Pain: A Randomized, Double-Blind, Placebo-Controlled, Crossover Study. Pain 2004;108:17-27.

15. Huge $\mathrm{H}$, Lauchart $M$, Magerl W, et al. Effects of Low-Dose Intranasal (S)-Ketamine in Patients with Neuropathic Pain. Eur J Pain 2010;14:387-394.

16. Dubecq C, Taton P, Morand G. Intérêt de la Kétamine Intra Nasale Dans Le Traitement de la Douleur Aiguë du Blessé Traumatique. Méd Armées 2018;46:143-150. 
17. Yanagihara Y, Ohtani M, Kariya S, et al. Plasma Concentration Profiles of Ketamine and Norketamine after Administration of Various Ketamine Preparations to Healthy Japanese Volunteers. Biopharm Drug Dispos 2003;24:37-43.

18. Weber F, Wulf H, Gruber M, et al. S-Ketamine and S-Norketamine Plasma Concentrations after Nasal and IV Administration in Anesthetized Children. Paediatr Anaesth 2004;14:983-988.

19. Andolfatto G, Innes K, Dick W, et al. Prehospital Analgesia With Intranasal Ketamine (PAIN-K): A Randomized Double-Blind Trial in Adults. Ann Emerg Med 2019;74:241-250.

20. Stephen R, Lingenfelter E, Broadwater-Hollifield C, et al. Intranasal Sufentanil Provides Adequate Analgesia for Emergency Department Patients with Extremity Injuries. J Opioid Manag 2012;8:237241.

21. Sin B, Jeffrey I, Halpern Z, et al. Intranasal Sufentanil Versus Intravenous Morphine for Acute Pain in the Emergency Department: A Randomized Pilot Trial. J Emerg Med 2019;56:301-307.

22. Lemoel F, Contenti J, Cibiera C, et al. Intranasal Sufentanil Given in the Emergency Department Triage Zone for Severe Acute Traumatic Pain: A Randomized Double-Blind Controlled Trial. Intern Emerg Med. 2019;14: 571-9.

23. Blancher M, Maignan M, Clapé $C$, et al. Intranasal Sufentanil versus Intravenous Morphine for Acute Severe Trauma Pain: A Double-Blind Randomized Non-inferiority Study. PLoS Med 2019;16:e1002849.

24. Adelgais KM, Brent A, Wathen J, et al. Intranasal Fentanyl and Quality of Pediatric Acute Care. J Emerg Med 2017;53:607-615.

25. Borland M, Jacobs I, King B, et al. A Randomized Controlled Trial Comparing Intranasal Fentanyl to Intravenous Morphine for Managing Acute Pain in Children in the Emergency Department. Ann Emerg Med 2007;49:335-340.

26. Murphy AP, Hughes M, McCoy S, et al. Intranasal Fentanyl for the Prehospital Management of Acute Pain in Children. Eur J Emerg Med 2017;24:450-454.

27. Pasquier $P$, Dubost $C$, Boutonnet $M$, et al. Predeployment training for forward medicalisation in a combat zone: the specific policy of the French Military Health Service. Injury 2014;45:1307-11.

28. De Rocquigny G, Dubecq C, Martinez T, et al. Use of Ketamine for Prehospital Pain Control on the Battlefield: A Systematic Review. Trauma Acute Care Surg 2019;88:180-185.

29. Fisher R, O'Donnell D, Ray B, et al. Police Officers Can Safely and Effectively Administer Intranasal Naloxone. Prehosp Emerg Care 2016;20:675-680.

30. Galant J, Corcostegui SP, Commeau D, et al. Utilisation de la Voie Intra Nasale Pour L'Analgésie en Milieu Hostile: À Propos D'Un Cas. Proceedings of the Société Française de Médecine de Catastrophe - Session douleur et catastrophes. 2020 Janvier 30; Paris, France.

31. Pasquier P, Bazin S, Petit L. The French Syrette of morphine for administration to combat casualties. Br J Pain 2016;10:66. 
Figures

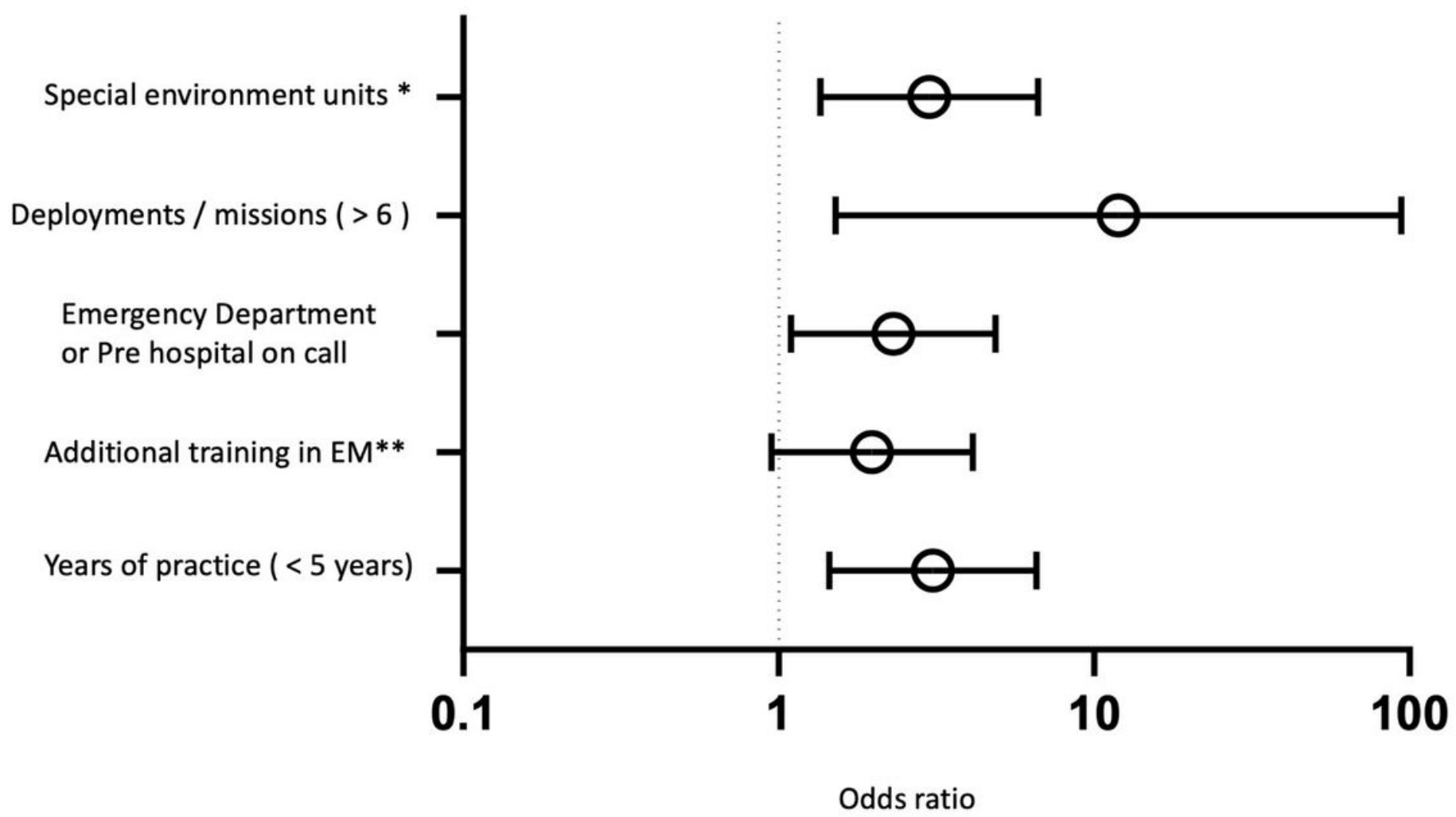

\section{Figure 1}

Multivariable analysis on knowledge of the IN route. Hosmer Lemeshow test, $\mathrm{p}$ value $=0,841$ Special environment units*: Physicians assigned to highly operational units or units working in austere environments. EM**: Emergency medicine 


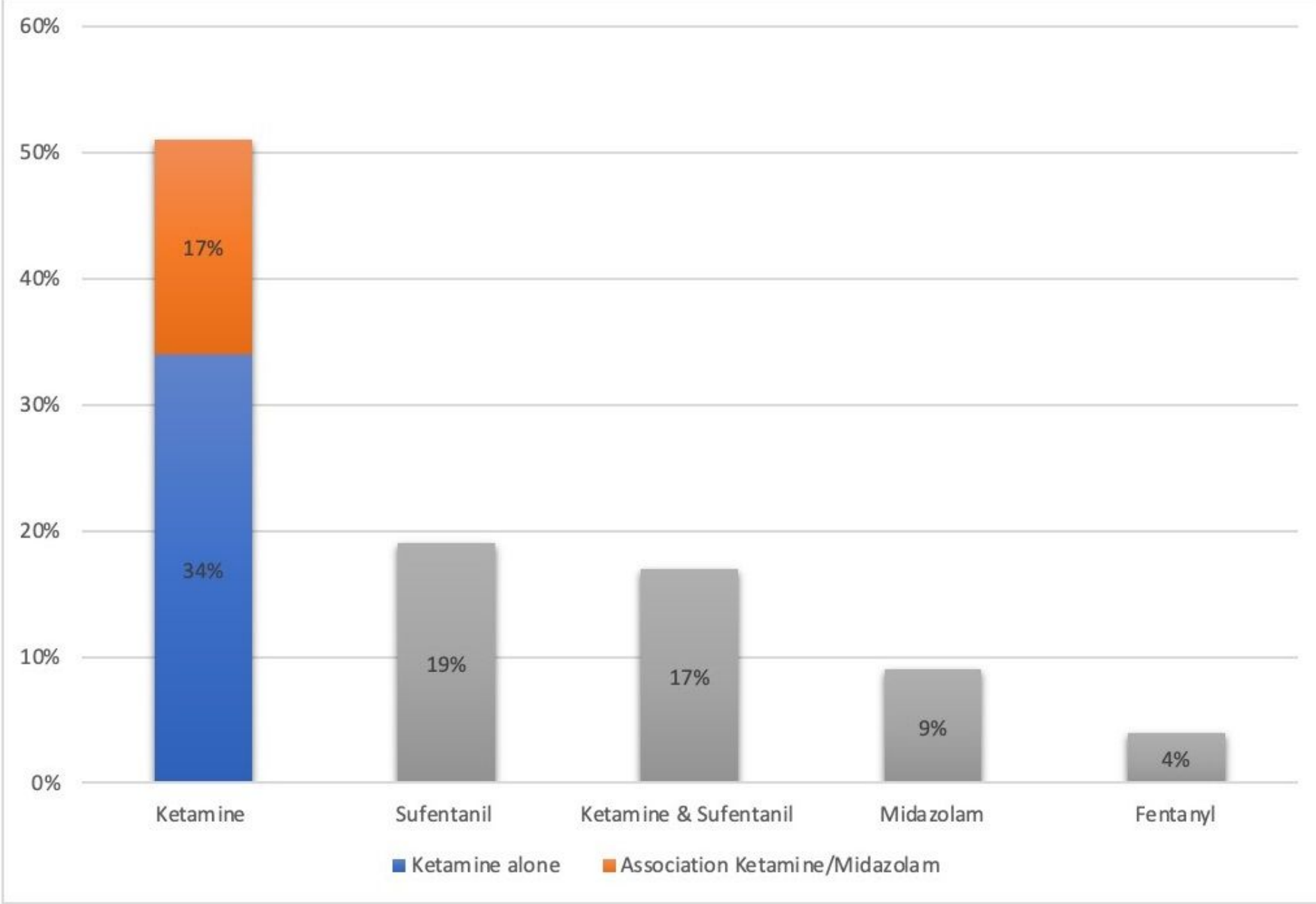

\section{Figure 2}

Drugs used by military physicians

\section{Supplementary Files}

This is a list of supplementary files associated with this preprint. Click to download.

- AnnexA.docx 